\title{
La Construcción en los siglos XVI a XVIII: la profesión de Aparejador, sus competencias
}

\author{
Francisco julio Arenas Cabello*
}

\begin{abstract}
RESUMEN ABSTRACT
La profesión técnica más antigua de España desempeñó un importante papel en la construcción en los siglos XVI-XVIII, en particular, en las trazas y ejecución del

Monasterio de El Escorial, $y$ en las grandes obras de reyes y nobles. Sin embargo, la creación de las Reales Academias rompe con los cánones gremiales en que los Aparejadores ocupaban una posición jerárquica superior a la clásica división funcional del trabajo.

The older technical profession of Spain played an important role in the construction in centuries XVI-XVIII, individual, the plans and execution of the Monastery of the Escorial, and in great works of kings and noble. Nevertheless, the creation of the Real Academies breaks with gremial canon in which the Aparejadores occupied a hierarchic position superior to the classic functional division of the work.
\end{abstract}

\section{INTRODUCCIÓN}

Las siguientes líneas pretenden resaltar la brillante labor que ejercen unos ilustres Aparejadores ${ }^{1}$ en la construcción del siglo xvl; en especial, en las trazas y ejecución material del Monasterio de El Escorial, su organización en las corporaciones gremiales y su jerarquía en la división funcional del trabajo.

Asimismo, tienen por objeto analizar la decadencia de nuestro país desde un contexto político, social y económico, y su repercusión en los estamentos gremia-

* Doctor en Derecho y Arquitecto Técnico. Profesor Derecho Civil. UNED.

1 Los Aparejadores - profesión sin par y a extinguir- cambian de denominación formal a la luz de la Ley 2/1964, de 29 de abril, de Reordenación de las Enseñanzas Técnicas; a este respecto, los Aparejadores se convierten en ARQUITECTOS TÉCNICOS, dando origen a la titulación de Arquitecto Técnico. 
les, previos a la instauración de las Reales Academias. El monopolio impuesto por éstas, eclipsa la labor desarrollada por los gremios hasta su total y definitiva desaparición.

La fundación de la Real Academia de San Fernando abrirá las puertas a las luchas enconadas entre Arquitectos y Maestros de Obras durante varios siglos. El triunfo de los primeros y la supresión, provisional, de los segundos permitirá, ya entrado el siglo xIX, la creación del título oficial de Aparejador.

Lo cierto es que la Real Academia no emite título alguno bajo la figura de Aparejador, tan sólo constituye una mera forma de intervención, un cargo, mediante el cual se permite alcanzar la titulación oficial de Arquitecto o Maestro de Obras, quedando pues atrapado entre dos mundos profesionales: el gremial y el académico.

Sin embargo, y a pesar de su status profesional, un tanto ambiguo, el Aparejador sigue consolidándose en las grandes obras de reyes y nobles en una posición jerárquica superior a la tradicional categoría de las Corporaciones gremiales.

\section{LA CONSTRUCCIÓN EN EL SIGLOXVI}

El siglo XVI constituye el Siglo de Oro para una serie de ilustres Maestros de la Construcción que ejercen la profesión bajo la figura de Aparejadores en las grandes obras de reyes y nobles. Un ejemplo manifiesto de ello puede observarse en las incidencias del proceso constructivo de la gran obra de El Escorial, en la actividad profesional ${ }^{2}$ de un importante grupo de Aparejadores especializados en cantería, albañilería, carpintería..., muchos de los cuales se promocionarán y pasarán a ocupar cargos de Maestros Mayores, convirtiéndose en genuinos Arquitectos al servicio del Rey, de las Corporaciones, de los Cabildos y Catedrales.

No obstante, el primer acaecimiento conocido del término Aparejador se remonta hacia la primera mitad del siglo xv, en la losa que cubre el sepulcro de Guillén de Rohan, concretamente en una capilla de Santa Clara de Tordesillas, se esculpe:

2 Como cualificación profesional establecida, la figura de Aparejador no aparece nunca entre las categorías que constituyen la clásica escala profesionaì de los gremios de la construcción. Lo mismo que la de Arquitecto, la cualificación profesional de Aparejador se explicita y adquiere consistencia y cuerpo específico sólo en las grandes obras de los reyes y nobles. A este respecto, cfr. MARCOS ALONSO, J. A: La estructura productiva del Sector de la Construcción y la profesión de Aparejador y Arquitecto Técnico, volumen IV-I, Primera parte. Evolución histórica, Madrid, Consejo Superior de Colegios Oficiales de Aparejadores y Arquitectos Técnicos, 1974, págs. 29 y 30. Acerca de la evolución histórica de la figura de Aparejador, cfr. ARENAS CABELLo, F. J: El Régimen Jurídico de la profesión de Arquitecto Técnico y Aparejador, Madrid, Dilex, 2003, págs. 23-56. 
«Aquí yace Guillén de Rohan, maestro de la iglesia de Leon et apareiador desta capilla ${ }^{3} . »$

La profesión o cargo de Aparejador convive en ese momento con otras cualificaciones profesionales - si bien sus funciones no están claramente definidas, por lo que persiste confusión entre unos y otros- que intervienen en el proceso constructivo a partir de la Edad Media, a saber ${ }^{4}$ :

- Maestro de Obras ${ }^{5}$. Locución que, de modo genérico, define a todos los constructores (Arquitectos, Alarifes, Aparejadores y Albañiles) que derivan de esta profesión, y cuyo cometido alcanza la ejecución de todo tipo de construcciones (edificaciones y obras públicas), concurriendo en éste las funciones de constructor, proveedor de materiales y director de las obras.

- Alarife. Locución de origen árabe que significa «el maestro, el entendido, el oficial». Sus funciones, de carácter público, se vinculan fundamentalmente con el municipio, en la ejecución de obras públicas ${ }^{6}$. En Madrid, durante todo el siglo XVI, como se aprecia en los libros de Acuerdos del Ayuntamiento, se conocen con el nombre de Alarifes a los ocho técnicos que nombran todos los años e intervienen como ingenieros y arquitectos en la Villa.

- Arquitecto. Hasta muy entrado el siglo XV1 —con la recepción de las ideas provenientes ciel Renacimiento italiano ${ }^{7}$ - no tiene vigencia entre nosotros el término Arquitecto, no existe una profesión específica de Arquitecto sino que los especialistas en el arte de construir se forman en el seno de los gremios adquiriendo la categoría de Maestros de Obras.

Es precisamente, en las construcciones de mayor complejidad, cuya diversidad de funciones exige una organización jerárquica, donde tiene su origen el Maestro Mayor o Director y máximo responsable de la obra; y, asimismo, la de Aparejador.

En este contexto de las obras reales, y dentro de la cualificación de Aparejador, surge una nueva jerarquía profesional que distingue en su seno a los Aparejadores

${ }^{3}$ Cfr. Portabales Pichel, A.: Maestros Mayores, Arquitectos y Aparejadores de El Escorial, Madrid, Editorial Rollán, 1952, pág. 128.

${ }^{4}$ En este sentido, cfr. Portabales Pichel, A.: Op. cit., págs. 127-132; e Izquierdo Gracia, P.: Evolución histórica de los estudios, competencias y atribuciones de los Aparejadores y Arquitectos, Técnicos, Madrid, Dykinson, 1998, págs. 19-28.

${ }^{5}$ Cfr. Bassegoda Nonell, J.: Los Maestros de Obras de Barcelona, Barcelona, Editores Técnicos Asociados, 1973, págs. 1 y ss.

${ }^{6}$ Cfr. Blasco Esquivias, B.: «El cuerpo de Alarifes de Madrid. Origen, evolución y extinción del empleo", Revista Anales del Instituto de Estudios Madrileños, (1990), págs. 467-493.

7 Cfr. Falcón Márouez, T.: El Aparejador en la Historia de la Arquitectura, Sevilla, Colegio Oficial de Aparejadores y Arquitectos Técnicos de Sevilla, 1981, págs. 19 y ss. 
Primeros y Aparejadores Segundos. La razón de ello obedece a la diversificada división funcional del trabajo. Ejemplos claros de ello se observan en el Palacio Real de Madrid y, sobre todo, en el Monasterio de el Escorial, que examinamos a continuación.

El Aparejador Primero se corresponde con el Maestro de Cantería o Aparejador de Cantería, responsable de la piedra a emplear en la construcción. Por su parte, el Aparejador Segundo es el Maestro o Aparejador de Carpintería, responsable de la madera para andamios, apuntalamientos...

\subsection{Especial referencia a la construcción del Monasterio de El Escorial}

Acerca del papel desempeñado por los Aparejadores en la construcción del Monasterio de El Escorial, conviene resaltar que su principal artífice viene representado por Juan Bautista de Toledo ${ }^{8}$, discípulo predilecto de Miguel Angel que ejerce en Roma como Aparejador en la Iglesia de San Pedro. Es el propio Juan Bautista quien revela que se inicia como Aparejador en una carta que desde El Escorial envía a Felipe II, el 9 de diciembre de 1564. El rey le ordena que vaya a Madrid y él contesta:

«...A lo qual digo q. yo hare todo loq. su magta. manda como es mi costumbre, y lo hago siempre, pero q. sepa q. no esta esta obra enestado q. pueda dexarla ocho dias sin verla, y hacer enella manualmente $c o$ ayuda delos aparejadores y algunos oficiales las cosas más dificiles./ Ansi q. enesta parte asido menester a hazer el oficio de aparejador como solia ser quando mancebo, para q. fuese todo acertado Conforme aloq. su magta. en las trazas dexo dibuxado y ordenado y mandado sin alterar algo dello, sino fuere con mucho mandato como rreza las dos listas..."

Archivo de Simancas, Escorial, leg. 2

Asimismo, el primero que alcanza en España la categoría de Arquitecto Oficial es Juan Bautista de Toledo, al iniciarse El Escorial, y con ella, la de Maestro Mayor; por su parte, Juan de Herrera nunca obtiene la categoría de Arquitecto, aunque sí en nóminas de 1580 , esto es tres años antes de finalizarse El Escorial ${ }^{9}$.

${ }^{8}$ Cfr. Portabales PiChel, A.: Los verdaderos artífices de El Escorial y el estilo indebidamente llamado Herreriano, Madrid, Gráfica Literaria, 1945, págs. 15 y ss.

${ }^{9}$ Cfr. Rodríguez Robledo, P.: Pedro de Tolosa, primer Aparejador de cantería de El Escorial, Madrid, Colegio de Aparejadores y Arquitectos Técnicos de Madrid, 1994. Esta autora pone de relieve que la falta de unanimidad en la historiografía se centra en tres puntos críticos:

1. Juan Bautista, artífice máximo e inspirador de la obra. En general, se le admite la «traza universal». De lo que se deduce del Memorial de Herrera es que lo único que no deja traza Juan Bautista, al morir, es de los tejados, como así lo revela LlaGUNo, E., II, 335. "Memorial de Herrera de 1584". 
La traza del Monasterio de El Escorial se debe a Juan Bautista de Toledo, nombrando para la obra de cantería como únicos Aparejadores Primeros: a Pedro de Tolosa; y, posteriormente, a Lucas de Escalante. Con aquél y con el de albañilería - Gregorio de Robles - coloca la primera piedra el 23 de abril de 1563, tras finalizar el primer replanteo de la gran obra.

Felipe II, poco después de haberse iniciado el Monasterio, reconoce que el edificio resulta pequeño para la grandeza que busca. Por ello, concibe la idea de reformar el proyecto, y así en el año 1564, Juan Bautista de Toledo, modifica el proyecto primitivo del Monasterio.

Por lo que a los Aparejadores se refiere, se tiene constancia de que Pedro de Tolosa, antes de servir a Felipe II, está levantando la iglesia del convento de Guisando. En El Escorial se descubre su maestría, midiendo, dando trazas y tasando, aún viviendo Juan Bautista; y muerto éste, dirige todo en unión de Gaspar de Vega - Maestro Mayor - y Lucas de Escalante, a quien Juan Bautista diera la máxima categoría al elegirlo de entre todos los buenos maestros españoles como discípulo para que le ayudase en las trazas de cantería.

De igual modo, se les confiere las prerrogativas que señalan las Instrucciones de 1569 y 1572, concediéndoles mercedes por el Rey como a insignes artistas. A estos dos, les sucede en la dirección de la obra de la Basílica, y al frente de escogidos maestros y admirados asentistas, el Aparejador Juan de Minjares, que por los méritos allí contraídos, es elevado a la categoría de Maestro Mayor de la Lonja de Sevilla, de la Alhambra de Granada y de las Caballerizas de Córdoba. Con éste, aparecen también en El Escorial Juan Bautista Monegro - escultor y mag-

2. Herrera, tracista: sobre este particular dice mucho el silencio de los historiadores; por otra parte, nos encontramos ante la especulación sobre sus títulos y la atribución de trazas sin firmar. En 1563 se le nombra, por cédula real, ayudante de Juan Bautista. Se le nombra «criado de su Magestad"s como hombre vinculado a la monarquia, como lo son los Tolosa, Juan Bautista, etc. Tampoco se le asciende a Maestro Mayor y, sin embargo, sí asciende el Rey a otros, como Pedro de Tolosa, Escalante, etc. Al menos hasta 1576, según Fray José de Sigüenza: «Historia de la Orden. Fundación», las obras están a cargo de los dos Aparejadores, Escalante y Pedro de Tolosa. Trazas firmadas de Herrera, según los estudiosos, sólo existen las de los tejados, y la casa de los oficios.

3. El tercer punto crítico corresponde al papel desarrollado por los Aparejadores, fray Antonio y los Priores. La figura de Tolosa, como la de los demás Aparejadores, se encuentra sumergida en el problema de fondo de la historiografía escurialense. En tanto ésta no desvele el tópico «estilo herreriano", no se comprenderá la magnitud de la fábrica de El Escorial.

Finalmente, en sus conclusiones, págs. 115 y 121 , resalta que Pedro de Tolosa es uno de los principales artífices de El Escorial, y que le corresponde gran parte de la ejecución, hecha antes y después de 1576, por haberse seguido sus planos, monteas y condiciones, pero que su figura aparece oscurecida por el mito herreriano creado por Llaguno; que Tolosa, y no Herrera, es el primer divulgador del estilo creado en El Escorial, en las provincias de Ávila y Valladolid; y que las figuras de Herrera y Tolosa vienen confundiéndose en edificios atribuidos tradicionalmente a Herrera, como supuesto creador de El Escorial, cuyo estilo es conocido con el nombre de «Herreriano.» 
nífico artífice- que como premio es nombrado Aparejador del Alcázar de Toledo, y Diego de Alcántara que llega a ser Maestro Mayor del Monasterio de Uclés ${ }^{10}$.

La profesión de Aparejador perdura a lo largo de los siglos XVII y XVIII —siempre en el marco de las Casas y Sitios Reales o de las grandes obras de reyes y nobles-con la misma organización estructural y funcional que se observa en la obra de El Escorial, esto es, como asistente inmediato del Maestro Mayor o Arquitecto, como responsable de la ejecución de sus trazas y órdenes, y sustituyéndolo en ausencia de aquellos:

Apuntamientos para lo de la Fabrica del Monasterio de Sant Lorencio. Enero 1562. Maestro mayor de la obra, tiene Vuestra Magd. Mandado que sea Joan Bautista de Toledo y quel, quando estuuiere ausente dexe en su lugar, el aparejador, o maestro que le pareciere, quedandole libertad de poderle mudar, acabada de resoluer la traca siendo Vuestra Magd. Seruido seria bien que tomasen trauajo de llegarse al Escurial para resoluer el assiento que se a de dar a la Yglesia y Monasterio...

A.G.S. Obras y Bosques. Legajo núm. 2.

Por lo que se desprende de los documentos de la época, puede decirse que si bien es cierto que el Maestro Mayor está capacitado para proyectar, dirigir y hasta contratar, y que el Aparejador viene a ser el que ordena los elementos de la obra, y al frente de los operarios la ejecuta, aunque en dependencia siempre de la orientación y mando del Maestro Mayor; no es menos cierto, sin embargo, que tal jerarquía -presente únicamente dentro de la obra - responda a una total separación de los derechos y obligaciones de uno y otro, y ello porque frecuentemente el que ejerce de Maestro Mayor en una parte, actúa bajo el cargo de Aparejador en otra, y viceversa ${ }^{11}$.

\section{LAS CORPORACIONES GREMIALES}

En la Edad Media, a impulsos del espíritu cristiano, surgen las Corporaciones gremiales, cuyo origen se remonta a los talleres que en los primeros siglos se asientan en los grandes monasterios, donde mezclados hombres libres y siervos aprenden y practican las artes y oficios.

${ }^{10}$ Cfr. Portabales Pichel, A.: Maestros Mayores..., Op. cit., pág. 133. Asimismo, el propio Pedro de Tolosa llega a ser nombrado Maestro Mayor del Monasterio de Uclés.

${ }^{11}$ Cfr. Portabales Pichel, A.: Idem, págs. 128 y 129; e IzQuierdo Gracia, P.: Op. cít, pág. 28. Así, en las obras de la catedral de Salamanca se nombran Maestro Mayor a Juan Gil de Hontañón, y Aparejador a Juan Campero; a su vez, éste es nombrado Maestro Mayor de las obras que el cardenal Cisneros Levanta en Torrelaguna, Madrid. 
Las poblaciones nacidas a la sombra del Monasterio se distribuyen en calles, en cada una de las cuales viven los de un mismo oficio, y de éstos toman aquéllas los nombres.

La Cofradía constituye durante el siglo XIII y xIV la fórmula ordinaria de las asociaciones obreras. Sus ordenanzas y reglamentos nos presentan al obrero cumpliendo un fin religioso ${ }^{12}$.

Pero además del fin religioso, existe, por la fuerza de esa organización, un medio de defensa, mutuo apoyo y una representación política en el Concejo de la Ciudad. El Gremio reglamenta y distribuye el trabajo, determina el número de maestros, oficiales y aprendices, y fija los exámenes a que deben someterse unos y otros para adquirir los distintos grados.

En muchos oficios no es obligatorio someterse al grado de oficial. El aprendiz que se considera con méritos y aptitudes para ser maestro solicita el examen ante los del Gremio y otros maestros; y, después de las correspondientes pruebas teóricas y prácticas, si lo merece, le conceden el título de Maestro, que representa la máxima categoría a que puede aspirar el artista.

Los primeros gremios se caracterizan por su vinculación con los municipios ${ }^{13}$. Esto se explica teniendo en cuenta la vieja organización municipal, en la que cada Ayuntamiento forma una unidad política y administrativa, casi un pequeño estado, con facultades incluso para conceder títulos. Así, nos encontramos que en los Fueros municipales se regulan los gremios, aunque se limitan a reconocer la existencia de los distintos oficios, no como entidad ni como corporación, sino como una actividad que precisa de una regulación.

El Fuero de Cuenca, por ejemplo, contiene disposiciones concretas para muy diversas profesiones. Entre los oficios relacionados con la construcción, alude expresamente a los Maestros de Obras (Capítulo XLII, I), carpinteros, Maestros de las paredes y tejadores (Capítulo XLII, II) y Maestros de los ladrillos y las tejas (Capítulo XLII, XIII).

12 En este sentido, cfr. SÁnCHez-ArCilla, J. y Montanos FerRin, E.: Historia del Derecho y de las instituciones, Madrid, Dykinson, 1991, pág. 146; MOLAS RIBALTA, P.: Los gremios barceloneses en el siglo xVIII. La estructura corporativa al comienzo de la Revolución Industrial, Madrid, Confederación Española de Cajas de Ahorro, 1970, pág. 97; y Tramoyeres Blasco, L.: Instituciones gremiales. Su origen y organización en Valencia, Valencia, Imprenta Doménech, 1889, pág. 25.

${ }^{13}$ Cfr. FaubelL, V.: «Notas sobre la formación profesional en España», Revista de Ciencias de la Educación, 84, (1975), págs. 390. 


\subsection{Organización interna de las Corporaciones Gremiales}

En torno a su organización interna, conviene destacar que los gremios o cofradías (términos análogos) se rigen por ordenanzas o estatutos especiales, a cuyo régimen juridico deben someterse sus integrantes. Estas ordenanzas son, en principio, diferentes para cada profesión y ciudad, sin embargo, en la práctica existe entre ellas relativa afinidad.

La dirección de la organización queda a cargo de una Junta compuesta por varios individuos o prohombres. El máximo representante del gremio se denomina Maestro Mayor y los restantes individuos de la Junta, Mayorales. En línea descendente se encuentran los Escribanos, Síndicos ${ }^{14} \ldots$

El Maestro Mayor ostenta la suprema autoridad y administración de todo lo relativo al oficio que preside; convoca sesiones, representa a la corporación ante las autoridades, y simboliza dentro de la Junta el poder supremo. Sus funciones duran un año y son de tres tipos:

- Económicas, Administrativas y Técnicas.

Igualmente, el Maestro Mayor cuenta con el auxilio, para el ejercicio de estas funciones, de otros cargos, a saber ${ }^{15}$ :

- Clavario: Análogo al depositario o contable en las sociedades modernas. Su cargo suele durar un año.

- Prohombres: Equivalente a los vocales de las juntas directivas modernas. Tamibién suelo durar un año.

- Oidores de cuentas: Examinan y fiscalizan los libros de cuentas del gremio.

- Síndico, notario o secretario: Redactan las actas de los consejos, de los encartamientos y de los exámenes.

- Veedores: Tienen por misión visitar los talleres del oficio e inspeccionar las obras que se ejecutan.

Con respecto a los artesanos, los gremios distinguen tres categorias, con prerrogativas diferentes, no pudiendo pasar de una categoría a otra sin el previo cumplimiento de una serie de presupuestos. Estas categorias son las siguientes:

- Aprendices, Oficiales y Maestros ${ }^{16}$.

14 Cfr. Tramoyeres Blasco, L.: Op. cit., pág. 126.

15 Cfr. Quetglás GayÁ, B.: Los gremios de Mallorca, siglos XII-XIV, Palma de Mallorca, Imprenta Politécnica, 1980 , págs. 32 y 33.

16 Sobre estas categorías y la formación que reciben, cfr. TRAMOYERES BlAsCo, L: Op. cit., págs. 212 y ss.; García Morales, M. V.: El oficio de construir: Origen de profesiones. El Aparejador en el siglo XVII, Madrid, Colegio Oficial de Aparejadores y Arquitectos Técnicos de Madrid, 1990, págs. 18-28; e IzQUIERDO Gracia, P.: Op. cit, págs. 44 y ss. 
Para integrarse en el gremio es necesario ser Oficial, en realidad, los Aprendices no pertenecen, pero es condición indispensable ejercerlo con algún miembro de la institución correspondiente.

Por lo que se refiere a los contratos que regulan las relaciones entre Maestro y Aprendiz, cabe citar las denominadas «Cartas de aprendizaje», donde se recogen los derechos y obligaciones de cada parte, formalizados en escritura pública, ante escribano.

Respecto al período de aprendizaje, en los gremios de la construcción, se exigen alrededor de cuatro años; superado éste, se asciende a la categoría de Oficial, en la cual se debe permanecer un determinado tiempo, generalmente dos años (período de práctica), que comienza desde el momento en que el Aprendiz se inscribe en el registro.

Finalmente, la categoría de Maestro supone superar un examen de suficiencia, convirtiendo así al Maestro en miembro activo del gremio; obtenido el título de Maestro, se puede adquirir taller propio, contratar obras, y de entre los más capacitados Maestros de Obras salen los futuros Aparejadores, Maestros Mayores y Arquitectos.

\section{LA CRISIS DE LOS GREMIOS ANTE LA CREACIÓN DE LA REAL ACADEMIA DE SAN FERNANDO. DOS MODELOS ANTAGÓNICOS}

La imposición de un nuevo orden profesional, con el nacimiento de la Real Academia de Nobles Artes de San Fernando, hiere de muerte a las arraigadas Corporaciones gremiales.

La posición privilegiada del nuevo orden, otorgando títulos oficiales y la ventajosa posición que le confieren las leyes, relega a un segundo plano la actividad profesional de los gremios. A éstos, sólo les queda una fuerte oposición al nuevo estado de cosas que permite demorar en un siglo su total desaparición.

Lo cierto es que la expedición por la Academia de los nuevos títulos oficiales de Arquitecto y de Maestro de Obras no incorpora, injustamente, la cualificación de Aparejador. Cien años después de la creación de la Academia aparece la titulación de Aparejador entre los nuevos Arquitectos y Maestros de Obras académicos como la absoluta hegemonía legal del nuevo orden profesional sobre los arcaicos gremios.

Desde un contexto político, socio-económico debe analizarse la evolución del proceso constructivo del tradicional modelo gremial del maestro-empresario ${ }^{17}$. El

17 A este respecto, cfr. Marcos Alonso, J. A.: Op. cit., pág. 23. 
Maestro de Obras gremial, el Arquitecto del tiempo, asume a la vez ambos tipos de funciones; en su sueldo como «maestro» o en el contrato que le vincula al encargante quedan incluidos, no sólo lo que hoy se puede llamar sus honorarios, sino también los sueldos que él ha de pagar al conjunto de los que trabajan a sus órdenes en la construcción; él es el responsable tanto del diseño y la dirección de las obras, como del aprovisionamiento de los materiales, de la responsabilidad de los obreros, etc.

Ahora bien, la definitiva configuración del Arquitecto como «experto» en unos saberes y en unas funciones específicas, dentro del proceso constructivo, va a contribuir de forma gradual a la separación del tradicional modelo gremial del maestroempresario.

Precisamente, es en el marco de las grandes obras donde va tomando cuerpo un nuevo mundo profesional, simbolizado por la figura del arquitecto-artista, que termina por subordinar y aniquilar de la escena de la construcción al viejo mundo gremial.

Por el contrario, en el ámbito de la construcción normal prevalece el modelo gremial, si bien el antagonismo patente de los modelos contribuye a que el modelo organizativo y profesional termine por imponerse como el único sistema válido para toda clase de obras.

\subsection{Circunstancias que explican la decadencia de los Gremios}

Lo cierto es que el modelo de división de trabajo no es el único elemento que pueda explicar, per se, la decadencia del sistema arcaico gremial, concurren asimismo otras circunstancias que merecen destacarse, a saber ${ }^{18}$ :

1. La decadencia económica y política de España en el siglo xVIII y las reformas propuestas, en relación con los gremios, por CAMPOMANES y JOVELLANOS.

CAMPOMANES intenta romper con la rigidez técnica y didáctica de las corporaciones gremiales, sin pretender acabar con éstos, tratando de mejorar sus métodos. Así, lo explica en el siguiente texto ${ }^{19}$ :

«La parte técnica o facultativa de las artes no está sujeta a ordenanzas, porque admite continuas variaciones a medida que los oficios adelantan o decaen, y, como depende del entendimiento, sus combinaciones son producto del discurso

${ }^{18}$ Cfr. Marcos Alonso, J .A.: Idem, págs. 25 y 26.

${ }^{19} \mathrm{Cfr}$. CAmpomanes, CONDE DE: Discurso sobre la educación popular de los artesanos y su fomento, Madrid, Imprenta Sacha, 1772, págs. 249 y 250. 
y no de la acción de la ley (..).. La parte técnica se ha de animar con instrucción, deducida de los libros de cada arte y de la aplicación de los artistas a mejorarla (...). Si los artífices españoles quedasen reducidos a un método perpetuo e invariable de enseñar y aprender las artes y oficios, y las manufacturas extranjeras libres de semejante coartación, esta fijación inutilizaría nuestras fábricas, ganando las invenciones y géneros que viniesen de fuera, por ser más conformes al gusto presente».

Asimismo, JovelLANOS considera que los gremios más que favorecer los impuisos de los nuevos procesos industriales, constituyen un verdadero obstáculo, y de este modo escribe ${ }^{20}$ :

«Reunidos sus profesores en gremios tardaron poco en promover su interés particular con menoscabo del interés común. Con pretexto de fijar la enseñanza establecieron las clases de oficiales y aprendices; con el de testificar al público la sufjciencia de quienes le servían, erigieron las maestrías; y para asegurarse de engaños inventaron preceptos técnicos, prescribieron reconocimientos y visitas, dictaron leyes económicas y penales, fijaron demarcaciones, y en una palabra redujeron las artes a la esclavitud, estancaron su ejercicio en pocas manos, y separaron de él a un pueblo codicioso que las buscaba con ansia por participar en sus utilidades».

2. La nueva concepción del Estado moderno y el papel preponderante de las monarquias absolutas.

El centralismo y la cultura «universalista» de la llustración, como ejes centrales de la política ejercida por los Reyes, rompen de manera absoluta contra el localismo y el particularismo que constituyen la base y el ámbito de la autonomía de los gremios.

El Arquitecto académico se constituye en el verdadero garante de la Ciencia, la Razón, el Arte, edificadas sobre bases válidas universalmente, a diferencia del modelo gremial que representa los saberes empíricos y tradicionales. El antagonismo de estos dos modelos se manifiesta por el carácter de «artista» y de «científico» del Arquitecto de la llustración, y por el carácter «artesano» y puramente «práctico» del Maestro gremial.

3. El desarrollo de una burguesía que será primero comercial y luego industrial, y la aparición de grandes mercados y recursos de capital que chocan con la estructura gremial de la sociedad.

Como pone de manifiesto MARCOS ALONSO ${ }^{21}$, con el empleo de grandes sumas de dinero, surge en las monarquías absolutas la pasión de los grandes edificios

${ }^{20}$ Cfr. De Jovellanos, G. M.: Informe dado a la Junta de Comercio y moneda sobre el libre ejercicio de las artes, Madrid, Obras publicadas e inéditas. Colección hecha e ilustrada por Cándido Nocedal, BAE-Rivadeneyra, 1858 , volumen 50 , págs. 33-45.

${ }_{21}$ Cfr. Marcos Alonso, J. A.: Idem, pág. 26 
monumentales «para gloria y honor del Rey»; la nación, el Estado, son del Rey; lo que se hace, lo que se construye, redunda en gloria de la persona real y de sus reinos; la pasión por construir se convierte en apetito de gloria para el monarca, pero también para el artista que traduce y plasma sus deseos en monumentos concretos.

Todos estos factores explican que el «nuevo arquitecto», procedente de los Maestros gremiales - los menos-y de las Corporaciones gremiales pero con formación artístico-humanista, recabe para sí la mayoría de los encargos de las obras reales.

Sin embargo, como señala PORTABALES ${ }^{22}$, los nuevos titulados de la Academia salen fortalecidos por los privilegios otorgados por los Reyes, pero al mismo tiempo perciben la debilidad de sentirse sin tradición y sin historia. Por ello, siguen confiando las Corporaciones y los particulares sus obras a los Maestros gremiales. Así, la catedral de Toledo nombra en 1773, en contra de todas las órdenes, Aparejador a Eugenio López Durango, conservando dicho cargo hasta 1786, en que asciende a Maestro Mayor.

Esta rebeldía a las pragmáticas inquieta al Gobierno y, sobre todo, a la Real Academia de las tres Nobles Artes de San Fernando, obligando a mitificar la figura de Herrera como símbolo y como precedente histórico de la legitimidad del «nuevo Arquitecto académico».

Cea Bermúdez, probablemente de acuerdo con sus compañeros de Corporación, encuentra a Herrera, y, prescindiendo de todos los grandes artistas de El Escorial, lo muestra la mundo como el único y gran Arquitecto que, sin haberse formado en la Escuela de los Gremios, traza y ejecuta el primer edificio del Imperio español, considerándolo como iniciador de una escuela y un estilo: el herreriano..., lo hace humanista y filósofo, matemático... para hacernos creer que en aquel tiempo todo lo de arquitectura es obra y gracia de Herrera ${ }^{23}$.

22 Cfr. Portabales Pichel, A.: Los verdaderos artífices..., op. cit., pág. 186.

${ }_{23}$ Cfr. Portabales Pichel, A: Idem, págs. 190-191. Portabales intenta demostrar, a partir de una abrumadora base documental, la desmitificación histórica de Herrera, descalificando así las bases mismas sobre las que el nuevo Arquitecto construyó la legitimidad de su exclusivismo profesional. Pues, ni en la obra de El Escorial ni, en general, en la amplia obra constructiva de Felipe II puede decirse que Herrera tenga, como Arquitecto, el papel y la participación determinantes y decisivas que luego se le atribuyen. Los verdaderos artífices de El Escorial vienen representados, por el contrario, por Juan Bautista de Toledo y un grupo de Aparejadores - fray Antonio de Villacastín, Pedro de Tolosa y Lucas de Escalante, entre los más ilustres- que trabajan a sus órdenes y que, una vez muerto Juan Bautista, actúan prácticamente de Arquitectos bajo la dirección de fray Antonio de Villacastín, como hombre de confianza del Rey; cfr., asimismo, RodRíguez RoBlEDo, P.: Op. cit., pág. 112. Esta autora señala que el primero en desmitificar la figura de Herrera y reivindicar la de los Aparejadores y el obrero mayor Villacastín es el referido Portabales, con sus dos estudios documentales ya citados aquí en páginas anteriores, a los que siguen el de Zuazo Ugalde y Modino De Lucas, respectivamente, en sus obras: 


\section{FUNDACIÓN DE LA REAL ACADEMIA DE LAS TRES NOBLES ARTES DE SAN FERNANDO}

El 30 de mayo de 1757 por Real Cédula de Fernando VI (Novísima Recopilación, libro VIII, título XXII, ley I) se instaura oficialmente en España, tras varios intentos, la Real Academia de las Tres Nobles Artes de San Fernando, en Madrid ${ }^{24}$ -rompiéndose así con los tradicionales cánones gremiales-, con la radical oposición de la Congregación de Nuestra Señora de Belén ${ }^{25}$.

Por la misma Real Cédula quedan también establecidos los Estatutos de la Academia (Novísima Recopilación, libro VIII, título XXII, ley II), cuyo capítulo 33 dispone lo siguiente:

«... Mando que, desde el día de la fecha de este mi despacho, por ningún Tribunal, Juez o Magistrado de mi Corte se conceda a persona alguna título o facultad para medir, tasar o dirigir fábricas, sin que preceda el examen y aprobación, que le dé la Academia, de ser hábil y a propósito para estos ministerios; y qualquiera título que sin estas circunstancias se conceda, lo declaro nulo y sin valor ni efecto; y el que obtuviere, además de las penas en que han de incurrir todos los que practiquen las tasas y medidas sin título legitimo, quedará inhábil aun para ser admitido a examen por tiempo de dos años".

Por lo que respecta a la citada Congregación de Nuestra Señora de Belén, de gran prestigio, reacia a los dictados de la Academia, se prescribe lo siguiente:

«Prohíbo a todas las Juntas, Congregaciones o Cofradías establecidas o que se intenten establecer en mi Corte para reglar los estudios y la práctica de las Tres

Zuazo ugaLde, S.: Los orígenes del Real Monasterio, 1948:

«Son los monjes jerónimos, con los aparejadores, destacando J. Minjares y el lego Villacastín quienes levantan el templo, porque tanto la Iglesia como el resto de las obras sigue sin maestro mayor. Juan de Herrera no lo es nunca y por ello jamás llega a ser director de la gran fábrica, es siempre el arquitecto proyectista en la etapa final de la construcción del Monasterio."

DE LUCAS, M.: Los priores de la construcción de S. Lorenzo, 1964 (O.S.A.).

24 Cfr. Bedat, C.: La Real Academia de Bellas Artes de San Fernando (1744-1808), Madrid, Fundación Universitaria Española, Real Academia de Bellas Artes de San Fernando, 1989, págs. 336 y ss. Este autor afirma que la dictadura artística imperante de la Academia impone el estilo neoclásico sobre el barroco, que encuentra sus raíces en el seno de las Corporaciones gremiales, págs. 378 y ss.

${ }^{25}$ Esta Cofradía o Congregación de la Construcción integrada por Arquitectos, Aparejadores y otras categorías profesionales (la mayor parte de los Maestros distinguidos de los siglos XVII y XVIII pertenecen a ella), manteniendo en Madrid el monopolio de la enseñanza. Ante la inminente creación de la Academia, desde el Consejo de Castilla, aliado de la Congregación, se solicita a ésta en 1742 la elaboración de unas Ordenanzas, inaceptadas por la Academia, por las que debe regirse la «carrera» de la construcción. Evidentemente, es un último intento por parte de la Congregación de seguir manteniendo el monopolio en materia de expedición de títulos. Acerca de esta Congregación, cf. SIERRA Corella, A.: Breve reseña histórica de la Hermandad de Nuestra Señora de Belén y Huida a Egipto, Madrid, Dirección General de Arquitectura, Ministerio de la Gobernación, 1950, pág. 17; García Morales, M. V.: Op. cit., págs. 187 y 188; e IZQUIERDo Gracia, P.: Op. cit., págs. 60-66. 
Nobles Artes, y con especialidad la que se dice de Nuestra Señora de Belén, sita en la parroquial de San Sebastián de mi Corte de Madrid. Todos sus cofrades podrán continuar en los ejercicios de piedad y devoción que con aprobación legítima hayan abrazado; pero no podrán usurpar los títulos de Colegio de Arquitectos, Academia de Arquitectura u otro semejante, ni tasar, ni medir, ni dirigir fábricas, sin tener los títulos que quedan expresados, o presentarse al examen de la Academia para conseguirlos, bajo pena de cien ducados la primera vez, doscientos por la segunda y trescientos por la tercera".

Una serie de disposiciones posteriores suprimen los exámenes gremiales, y con la fundación de la Real Academia de San Carlos para el Reino de Valencia se concreta el nuevo orden corporativo de la Academia, marcando el carácter absoluto y radical, con que se plantea la abolición de las tradicionales instituciones gremiales ${ }^{26}$.

Así las cosas, lo cierto es que la Academia se configura oficialmente como único centro legal para expedir títulos: Arquitecto es el que supere los cursos completos de la Academia; y Maestro de Obras, el que revalide con examen el título concedido por otro organismo.

Finalmente, conviene subrayar que el modelo de Academia impuesto en España, siguiendo el modelo francés, se diferencia de forma notable al del resto de países europeos. En Francia, la Academia de Colbert monopoliza de forma exclusiva el título de «Arquitecto del Rey», quedando al margen del ámbito académico el resto de las construcciones no monumentales ${ }^{27}$.

La aparición del Arquitecto en aquel país cobra importancia con el favor de la monarquía absoluta, no obstante, ello no supone que hasta el siglo XIX reinase la mayor confusión - como en el caso de España- en la construcción de edificios, entre Arquitectos, empresarios, albañiles y la «gente de mundo». En 1895 no

${ }^{26}$ Cfr. Marcos Alonso, J. A.: Op. cit., págs. 32-42, quien afirma que el nuevo corporativismo profesional significa ante todo un golpe decisivo a las tradicionales autonomías locales y demás corporaciones estamentales, de aquí también la fuerte oposición que éste encuentra en la sociedad española, que obliga a los Reyes a reafirmar constantemente sus supuestos legales con nuevas disposiciones, pág. 49 . La causa de esta oposición se encuadra en el ámbito político-administrativo, estas instituciones locales no protegen al albañil contra el Arquitecto o Maestro de Obras académico, todo lo contrario, defienden el ámbito y la legitimidad de su autonomía local contrá el poder central, pág. 51. Igualmente, cfr. IzQUIERDO GRACIA, P.: Op. cit., págs. 71-79, quien señala que el control que deben realizar los Ayuntamientos, respecto de las pragmáticas, no es muy estricto. Así, entre los Ayuntamientos que incumplen estas disposiciones se encuentran el de Toledo (antes citado por PoRTABALEs) y los del Principado de Cataluña.

27 De hecho, el movimiento institucionalizador del título de Arquitecto, como título profesional en sentido moderno, comienza en Francia, donde Colbert establece en 1671 la primera Academia de Arquitectura - que monopoliza el título de Arquitecto únicamente para los Arquitectos del Rey, considerando a los demás como simples «maçons»--, para extenderse posteriormente, en el siglo XVIII, por toda Europa. $Y$ es que los maçons, cuya historia no es bien conocida por el carácter secreto que confieren a sus asociaciones, actúan en legítima defensa como reacción al cierre de los gremios. 
existe Ley alguna que proteja el título de Arquitecto, en 1940 se promulga la Ley instituyendo la Orden de los Arquitectos, a partir de entonces, nadie puede ser llamado Arquitecto si no está diplomado por una de las Escuelas reconocidas por el Estado.

Ahora bien, la profesión no se ejerce en régimen de monopolio, no se imponen los servicios de un Arquitecto; el derecho a construir pertenece a todo el mundo ${ }^{28}$.

\subsection{Los conflictos de competencias entre Arquitectos y Maestros de Obras}

Llama la atención que la Academia de San Fernando, fundada sobre la base de los principios de la llustración -en relación con la actividad profesional, esto es, convertir las profesiones propiamente dichas en profesiones «liberales», liberadas de las servidumbres gremiales- adopte por el contrario un sistema estructural de corte monopolístico y corporativo (cuyos titulados ejercen, en exclusiva, las funciones de tasar, medir, proyectar y dirigir obras), obligando a crear dos tipos de Arquitectos ${ }^{29}$ :

1. De un lado, los "Arquitectos-artistas", cuyo objeto es monopolizar la arquitectura monumental.

2. De otro, los «Maestros de Obras» académicos, responsables de las construcciones ordinarias.

Si bien es cierto que las competencias, en un principio, se hallan meridianamente delimitadas: arquitectura monumental y no monumental; no por ello las diferencias se resuelven. En 1787, veinte años después de la fundación de la Academia, sale a la luz la Real Orden (Novísima Recopilación, lib. VIII, tít. XXII, ley VII) que sienta las bases de un conflicto que finaliza a la postre con la desaparición del título de Maestro de Obras, permaneciendo únicamente el título de Arquitecto o «Maestro Arquitecto con todas las facultades del arte». En la citada Orden se establece lo siguiente:

«... Asimismo mando que los Arquitectos o Maestros mayores de las capitales y cabildos eclesiásticos principales del Reyno sean precisamente Académicos de mérito de San Fernando o San Carlos, si fuese en el Reyno de Valencia; para lo cual, siempre que haya vacantes en este empleo lo avisarán a las Academias..."

28 Cfr. Marquart, F., y DE MONTLibert, $\mathrm{CH}_{\text {.: }}$ «La arquitectura, una profesión en pleno proceso de cambio", Revista CAU, 6, marzo-abril (1971), pág. 66.

${ }_{29}$ Cfr. Marcos Alonso, J. A.: Op. cit., pág. 45. Este autor pone de relieve que la Academia presentándose como una superación del corporativismo gremial, adopta en realidad la misma estructura rígidamente corporativista de los gremios, sólo que trasladándola a un nuevo contexto y a una nueva escala: la del «universalismo gremial» que sustituye al localismo típico de la economía y actividad constructiva del estamentalismo gremial. 
En ella (Académicos de mérito) no se especifica expresamente el título de Arquitecto, pero implícitamente ha de suponerse así en la mayoría de los casos al exigir la condición de Académico de mérito.

Así las cosas, lo cierto es que se está diferenciando entre Arquitectos propiamente dichos y Maestros de Obras como Arquitectos de segunda categoría, pero facultados igualmente para proyectar y dirigir obras.

La Real Academia de San Fernando comunica a las otras Academias de provincias que desde 1796 resuelve dejar de expedir el título de Maestro de Obras y que el único título académico es, desde ahora, el de Arquitecto, si bien se permite que aquellos Maestros que hubiesen adquirido el título con anterioridad a esta fecha continúen ejerciendo como tales ${ }^{30}$.

Con el inicio del siglo XIX, aún queda más patente y manifiesta la verdadera distinción entre los dos títulos académicos: los Arquitectos con clase superior y los Maestros de obras con clase profesional media ${ }^{31}$.

No cabe la menor duda de que el próximo recurso legal de que harán uso los Arquitectos será la supresión del título oficial de Maestro de Obras y su sustitución por otro de nuevo cuño oficial, el de Aparejador, que examinamos a continuación.

\subsection{La situación de los Aparejadores antes y después de la instauración de la Real Academia de San Fernando}

Desde un punto de vista normativo, y previa a la instauración de la Academia, tan sólo la Ordenanza de 1742 -antes aludida, en nota a pie de página número 25 , en que la Congregación pretende dar respuesta a la Academia con el fin de seguir emitiendo títulos- hace referencia expresa a la figura del Aparejador. Así, su apartado 15 se expresa en los siguientes términos:

30 Informe sobre las reclamaciones de los Maestros de Obras, contra el Reglamento decretado por su Magestad, el 22 de Julio de 1864, Madrid, publicado por la Sociedad Central de Arquitectos. Imprenta de José M. ${ }^{a}$ Ducazcal, 1865. Asimismo, cfr. IGUAL UbeDA, A.: «Las Reales Academias de Bellas Artes de San Fernando y San Carlos y el Gremio de Albañiles de Valencia", Archivo de Arte Valenciano, (1957), págs. 57-76.

31 Cfr. BAsSEgoda Nonell, J.: Op. cit., pág. 16, quien sostiene que con la organización de la Academia y la Real Orden de 1817 «realmente se crea una subclase de Arquitectos, unos Arquitectos de segunda que quizá sean necesarios en la época de reconstrucción, pero que luego darán grandes quebraderos de cabeza a causa del abuso de atribuciones en que lógicamente incurren, ya que muchos de los Maestros de obras son expertos profesionales, a veces, de mayor talla que sus hermanos mayores, los Arquitectos». Asimismo, cfr. MARcos Alonso, J. A.: Op. cit., págs. 59 y 60. 
«15. Que no se admita a examen para Maestro Arquitecto a quien no tenga cuatro años de estudio teórico, o en la Academia que S.M. ha fundado en esta Corte, o con alguno de los arquitectos aprobados; y otros cuatro años de práctica asistiendo de aparejador en las obras de alguno de los expresados arquitectos."

De lo anterior se desprende lo que supra se apunta, esto es, bajo la figura de Aparejador no existe título alguno, sino que representa una forma de intervención, un cargo, y una vía para obtener la titulación oficial de Arquitecto y Maestro de Obras.

Con la imposición de la Academia, y tras polémicas reivindicaciones entre Arquitectos y Maestros de Obras, se crean a principios del siglo XIX dos nuevas titulaciones: la de Arquitecto y la de Aparejador Facultativo. Respecto a la segunda, las funciones que definen a esta titulación se alejan sustancialmente de las atribuciones del Aparejador, tanto de la etapa de las Corporaciones gremiales como de la Ordenanza antes citada. Atribuciones, más bien próximas, como expone GARCÍA MORALES, a las de un albañil común ${ }^{32}$.

Desde un contexto político socio-económico, la tesis de MARCOS ALONSO ${ }^{33}$ nos permite analizar la integración del Aparejador, bien simbolizado por el viejo Maestro gremial o por el Arquitecto académico.

En los siglos XVI-XVIII la actividad de la construcción se desarrolla sobre las categorías típicas de las Corporaciones gremiales, esto es, Maestro, Oficial y, con menor grado, Aprendiz. Si bien es cierto que la función de Aparejador también tiene cabida en este contexto, no es menos cierto que su verdadera vocación tiene carta de naturaleza en las grandes obras de reyes y nobles.

En este contexto, encontramos al Aparejador en una posición jerárquica superior, por debajo de ésta, se sitúan las categorías típicas gremiales antes aludidas.

Para finalizar, debemos concluir que la cualificación de Aparejador se sitúa a caballo entre los dos mundos profesionales, pero que se consolidan como Aparejadores reales, pertenecientes al nuevo mundo profesional simbolizado y centrado en el Arquitecto; por ello, el Aparejador de entonces no debe considerarse un antagonista del Arquitecto.

32 Cfr. García Morales, M. V.: Op. cit., págs. 188-191; e Izquierdo Gracia, P.: Op. cit., pág. 67.

33 Cfr. Marcos Alonso, J. A.: Op. cit., págs. 29-31. Frente a la tesis de este autor, nos encontramos la de Portabales PICHEl, A.: Los verdaderos artífices..., op. cit., págs. 184 y ss., en ella, sostiene que la Academia trata de eliminar y suprimir todo derecho a los Aparejadores. En cualquier caso, pensamos que lo verdaderamente cierto es que injustamente la Academia sólo expide títulos de Arquitecto y de Maestro de Obras, y no de Aparejador. 
